\title{
The Drop Weight Test Revisited: Characterization of the Crushability of Hot Sinter and Validation of the Approach with Natural Rocks
}

\author{
Wolfgang Öfner ${ }^{1}$ and Guido Zaunrith ${ }^{2}$ \\ ${ }^{1}$ Chair of Mineral Processing, Montanuniversitaet Leoben, Leoben, Austria \\ ${ }^{2}$ Montanuniversitaet Leoben, Leoben, Austria
}

Published online June 2, 2016

\begin{abstract}
The crushing behaviour of sinter from blast furnace operations is known to depend on its temperature. In order to characterize it, hot sinter was subject to single particle tests in a very basic drop weight tester. Additionally, a laboratory jaw crusher was sacrificed to work the same feed material. As the results regarding net energy input were not consistent, two common rocks were tested in comparison with both the drop weight and the jaw crusher. Although some discrepancies remained, the results with the rocks can basically be considered as consistent. This investigation illustrates some of the difficulties that can arise when established test methods are applied on material with deviant properties.
\end{abstract}

Keywords: Hot sinter, Comminution test, Drop weight, Jaw crusher

Wiederbelebung des Fallhammerversuches: Beschreibung des Zerkleinerungsverhaltens von Heißsinter und Überprüfen der Methodik anhand natürlicher Gesteine

Zusammenfassung: Das Zerkleinerungsverhalten von Sinter aus der Hochofenroute hängt bekanntermaßen von seiner Temperatur ab. Zu seiner Beschreibung wurde Heißsinter in einem sehr einfachen Fallhammer der Einzelkornzerkleinerung unterzogen. Das gleiche Aufgabematerial wurde auch einem Laborbackenbrecher aufgegeben. Aufgrund der nicht konsistenten Ergebnisse wurden ergänzend Vergleichsversuche mit zwei Gesteinsproben auf dem Fallhammer und dem Backenbrecher durchgeführt. Diese Resultate sind im Wesentlichen konsistent. Die beschriebenen Unter-

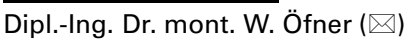

Chair of Mineral Processing,

Montanuniversitaet Leoben,

Franz-Josef-Straße 18,

8700 Leoben, Austria

E-Mail: wolfgang.oefner@unileoben.ac.at suchungen zeigen einige Probleme auf, wenn eingeführte Testmethoden auf Materialien mit vom Üblichen abweichenden Eigenschaften angewandt werden.

Schlüsselwörter: Heißsinter, Zerkleinerungsversuch, Fallhammer, Backenbrecher

\section{Introduction}

A blast furnace operation considered a crusher replacement in order to provide a lower maximum particle size on the sinter cooler. The aim of the original investigation was to provide a data set characterizing the crushing behaviour of the sinter which should be used in the actual design of a comminution circuit. As the crushing properties of sinter are known to depend on its temperature, tests should be carried out with hot samples immediately at the sampling location. The test device was required to be simple and sturdy, so a very basic drop weight tester was constructed.

During test work, a laboratory jaw crusher was sacrificed for comparison. Evaluation of the data showed large discrepancies between the results from drop weight and jaw crusher in terms of temperature effect. Also the particle size distributions (PSD) were consistent only from the crusher - with the drop weight, the fineness did not correlate with the energy input.

In a subsequent comparison of the jaw crusher and the drop weight with two common rocks, the results from the drop weight were consistent as well. However, there remains a large difference between these two types of comminution. These parts of the paper are based on test work for a bachelor's thesis [1] without further reference.

This investigation illustrates some of the difficulties that may be encountered when established test methods are applied to materials with deviant properties. 


\section{Materials and Test Procedures}

\subsection{Samples}

\subsubsection{Sinter}

The feed to the sinter strand is basically a blend of three different materials, viz. iron ore, limestone, and coke breeze. After thorough mixing, it is loaded onto a travelling grate. At the beginning of the sinter process the coke breeze on top of the feed layer is ignited by a gas burner. While travelling along the strand, air is sucked through the sinter feed. This creates a burning front in the feed moving from the top towards the grate. The sinter process proper ends at some distance before discharging from the belt. After this point, the sintered material is cooled by the permeating air. Therefore large temperature differences appear in the sinter before it reaches the sinter cooler; the lowest temperatures occurring in material from the top and the highest temperatures in the centre material at the bottom.

At the end of the grate the hot sinter breaks into lumps of up to half a meter in size and falls onto a rotary crusher. The crushed hot sinter may still contain pieces of $300 \mathrm{~mm}$ size when it is sieved at about $5 \mathrm{~mm}$ mesh size. Specimens of hot sinter were taken from this sieve just before being charged onto the rotary sinter cooler.

Although during sintering only the surface layer of the particles proper in the feed melts, they cannot be distinguished in sections of the sinter from this plant. An important feature of the sinter is its porosity which amounts to about $30 \%$ at a rough estimate.

The sinter tested in this investigation can be divided into several sample types: hot lumps taken from the sieve just before entering the sinter cooler and tested immediately; same as before but tested after cooling freely to ambient temperature (by radiation only, low rate of temperature change); particles after passing the sinter cooler (permeation of air, high rate of temperature change).

The lumps sampled were chosen only for their size. The single particle mass ranged from about 600 to $6,000 \mathrm{~g}$ each.

\subsubsection{Limestone}

The limestone originates from a quarry in Gotland, Sweden and was tested for its Natural Breakage Characteristics (NBC) in the EU project "Less Fines" with focus on minimum fines production during comminution in 2002 [2]. The rock at the mine site is categorized in four types, this sample being type $R$. The particles used in this investigation were taken from the size fraction $+32-40 \mathrm{~mm}$ of the first crusher product in Less Fines. Obviously, comparison with the historical data is possible without restrictions.

\subsubsection{Amphibolite}

The amphibolite is mined in the Waldviertel region in Austria. The sample was taken from stored product at the plant, namely crushed aggregate $+31.5-63 \mathrm{~mm}$. A sample from the same quarry had been investigated in the Less Fines project as well, but their likeness is unknown. Comparison with its historical data is therefore of limited use.

\subsection{Equipment}

\subsubsection{Drop Weight Tester}

As the drop weight tester was expected to experience rough conditions and high temperatures, sturdiness was one of its main design requirements. The location of the tests was to be somewhere in the plant in close proximity to the hot sinter, so it had to be modular and completely independent from any infrastructure as well.

These requirements were met by using $5 \mathrm{~mm}$ thick steel parts throughout and omitting any fancy moving or delicate features. The drop height, for example, was not adjusted by pulleys, but by holding the weight by hand and height control was performed by resting a marked rod on top of the particle under examination. Basically the tester comprises a tube $1 \mathrm{~m}$ high with $300 \mathrm{~mm}$ diameter, a base, and a cylindrical weight of $10 \mathrm{~kg}$. For placing the particle on the base of the tester and for removing the crushed matter, the tube was tilted.

\subsubsection{Jaw Crushers}

When the first results from the drop weight tests were somehow inconclusive, an old single toggle laboratory jaw crusher was sacrificed for crushing hot sinter on-site. As this clearly exceeded designed operating conditions of the apparatus, it was not fit for duty anymore due to mechanical issues. The gape of the crusher is $140 \times 100 \mathrm{~mm}$, gap width was $5 \mathrm{~mm}$ closed side setting (CSS). This crusher will be referred to as "Fuchs".

Crushing tests with cold sinter were done in the laboratory with both the Fuchs and the "Retsch" crusher. The latter provides a gape of $100 \times 100 \mathrm{~mm}$ and an adjustable gap width which was set to $28 \mathrm{~mm}$ CSS for sinter crushing. For the rock samples, CSS was $17.4,10.4$, and $6.5 \mathrm{~mm}$, respectively.

All crushing tests in this investigation were done in open circuit.

\subsubsection{Power Measurement}

For assessing the energy requirements of crushing, active power draw is measured on one phase by a digital multimeter, type Voltcraft M-4660M. Data is transferred to a computer at a rate of 1 sample per second. Crushing power was measured only in laboratory tests.

Calculation of the net crushing energy presumes symmetric load conditions in the three-phase AC system and that the losses measured as idle power draw apply during crushing as well. 


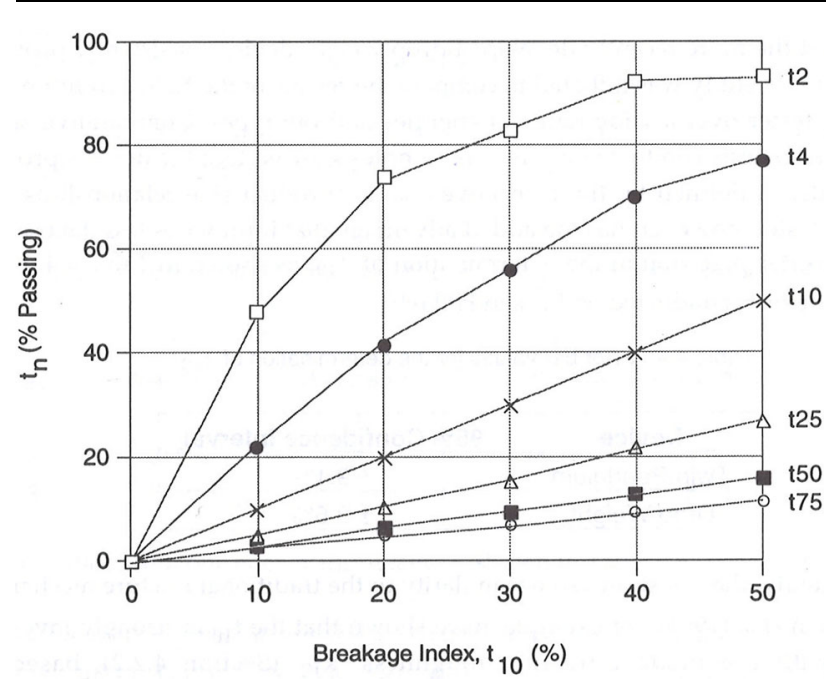

Fig. 1: Data reduction of breakage data - the scatter plot of $t_{n}$ vs. t10 [3]

\subsection{Test Procedures}

\subsubsection{The $t_{10}$ Modelling Concept}

A large number of comminution models of varying degree of complexity are documented in literature. Many flowsheet simulators use matrix calculations comprising a "selection stage" and a "crushing stage" for prognosis of resulting particle size distributions (PSD). This method is known as the population balance model and requires a substantial amount of test work for material characterization as well as dedicated software [3, pp 66-69].

The Julius Kruttschnitt Mineral Research Centre (JKMRC) in Brisbane, Australia, developed an easier approach by defining the parameter set of $t_{n}$ as the basis for estimating the PSD after comminution: $t_{n}$ is the passing (in $\%$ ) at $1 / n$ of the particle size before crushing [3, pp 78-81]. A number of single particle crushing tests are performed at different combinations of particle size and specific energy. Sieve analysis of the comminution products and evaluation of a set of $t_{n}$ values results in a chart like Fig. 1 . The desired size reduction translates into a certain value for $t_{10}$, which in turn can be used to read the entire particle size distribution from the chart in terms of the corresponding $t_{n}$. Energy requirement is characterized in this model by the relation of $\mathrm{t}_{10}$ and specific energy input (Fig. 2).

\subsubsection{Single Particle Tests}

The procedure of a particular single particle test was:

- documentation of the particle via weighing and a photograph

- crushing it by either drop weight tester or jaw crusher

- collection of crushed matter and letting it cool, if applicable

- sieve analysis

For sinter, the tests were organized in series of ten particles each, where usually conditions were tried to be kept

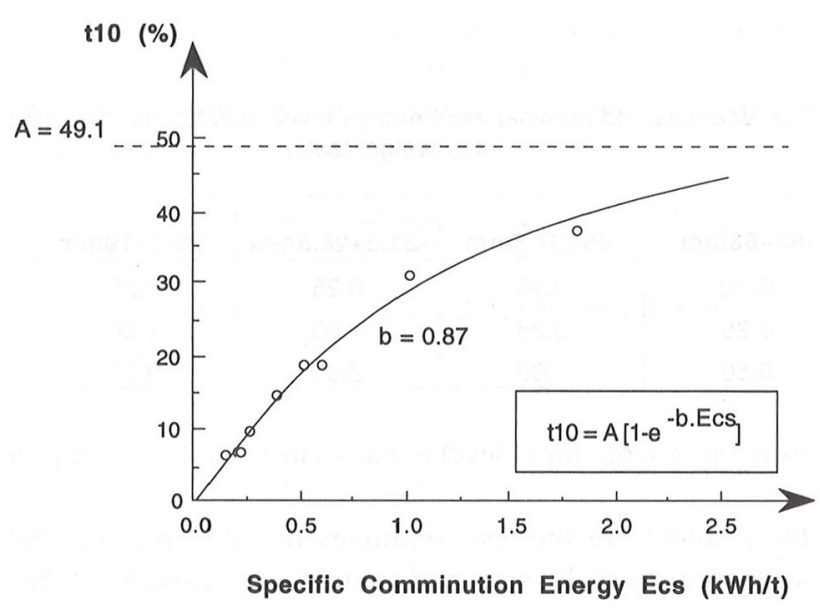

Fig. 2: Relation between specific comminution energy and the breakage parameter $\mathrm{t} 10$ [3]

as constant as possible. Information on sample temperature of hot sinter is partly available. Specific energy input is available for all drop weight tests. Measured power draw of the jaw crusher was considered unreliable - due to the short crushing cycle time of about $10 \mathrm{~s}$ per specimen at a data acquisition rate of one sample per second, temporal resolution is too low and on later tests idle power draw of the Fuchs crusher was fluctuating too much.

The series of single particle tests with limestone and amphibolite comprised 15 particles each at one of three energy levels.

The drop height was adjusted for the desired specific energy input. This ranged from 10 to $44 \mathrm{~J} / \mathrm{kg}$ per hit for sinter and from 1 to $4 \mathrm{~J} / \mathrm{g}$ for limestone and amphibolite. The factor of hundred of the energy level required for effective crushing is partly caused by the substantial porosity of the sinter and possibly complemented by internal stress or inherent fractures in the sinter lumps.

\subsubsection{Bulk Tests}

This type of test applies only to the limestone and the amphibolite samples and was done on the Retsch crusher with batches of $3 \mathrm{~kg}$ each. Gap width was set to 17.4, 10.4, and $6.5 \mathrm{~mm}$ CSS. This refers to specific energy of approximately 3,5 , and $8 \mathrm{~J} / \mathrm{g}$ for limestone and 2,8 , and $15 \mathrm{~J} / \mathrm{g}$ for amphibolite. As many of the amphibolite particles were able to pass the gap at the widest setting without breakage, results from its lowest energy level are not relevant.

\subsubsection{Five-particle Tests}

In some series, five lumps of sinter were fed to the crusher consecutively. Crushing conditions were the same as in single particle tests, but the crusher remained in load state for a longer time. This reduced the effect of the short crushing cycles in single particle tests considerably. 


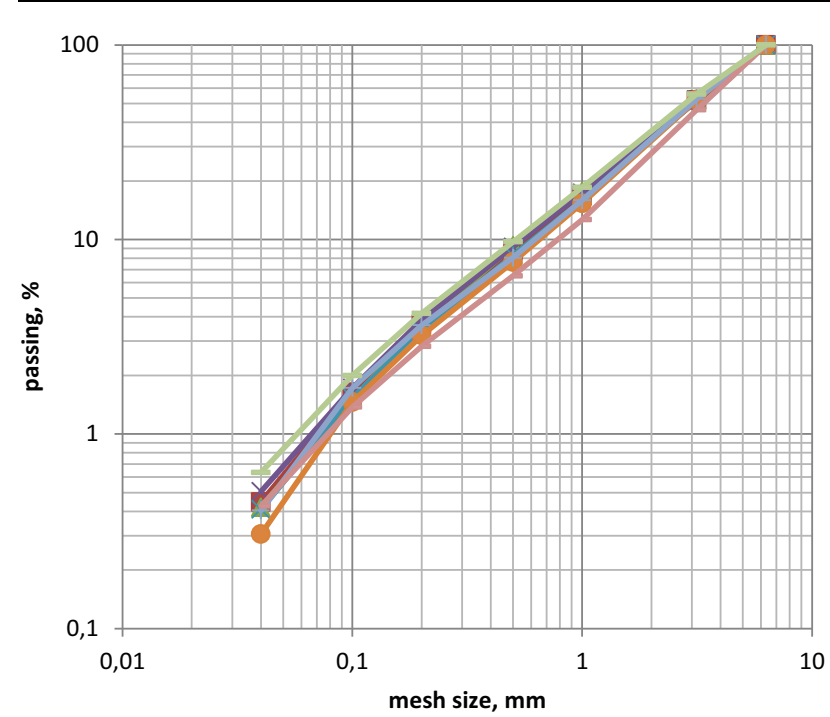

Fig. 3: Identical PSDs below $6.3 \mathrm{~mm}$

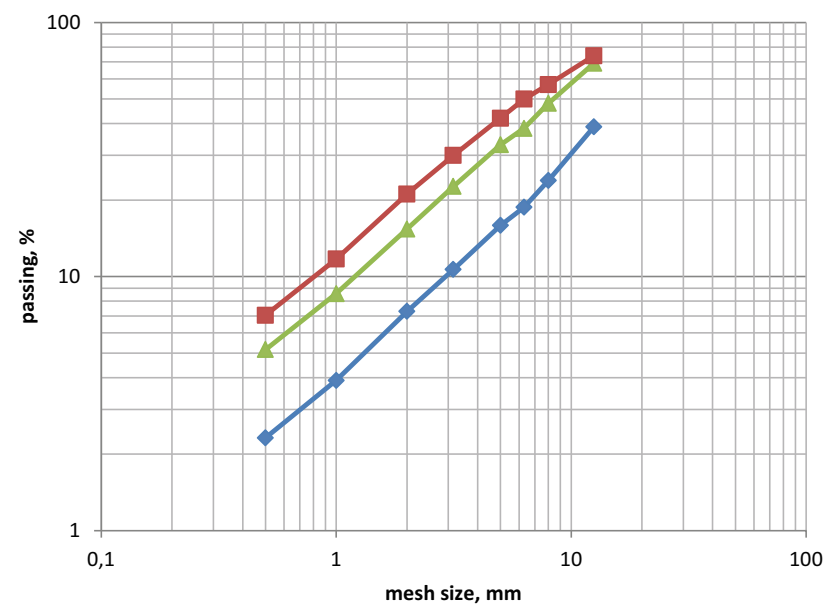

Fig. 4: PSD for drop weight tests of limestone at three different energy levels

\section{Resulting Particle Size Distributions}

\subsection{Sinter}

Manual sieve analysis was done separately for every singleparticle test, for the bulk tests and the five-particle tests. The mesh sizes ranged from 125 to 5 or $6.3 \mathrm{~mm}$, respectively.

As breakage of single parent particles at low specific energy levels generally results in only few large progeny particles, the coarse parts of the crushed PSDs suffer from very low statistical significance. This is reflected by the fact that within a given series of single particle tests at similar conditions the same particle size class may miss completely in one sample and abound in the next. The smaller the particle size in the PSD of the crushed material, the closer the separate PSDs get in terms of slope.

For additional comparison, the samples of one series were analyzed further down to $40 \mu \mathrm{m}$. Taking into account the wide variation of the PSDs above $6.3 \mathrm{~mm}$, they can be considered identical below $6.3 \mathrm{~mm}$ (Fig. 3). This illustrates

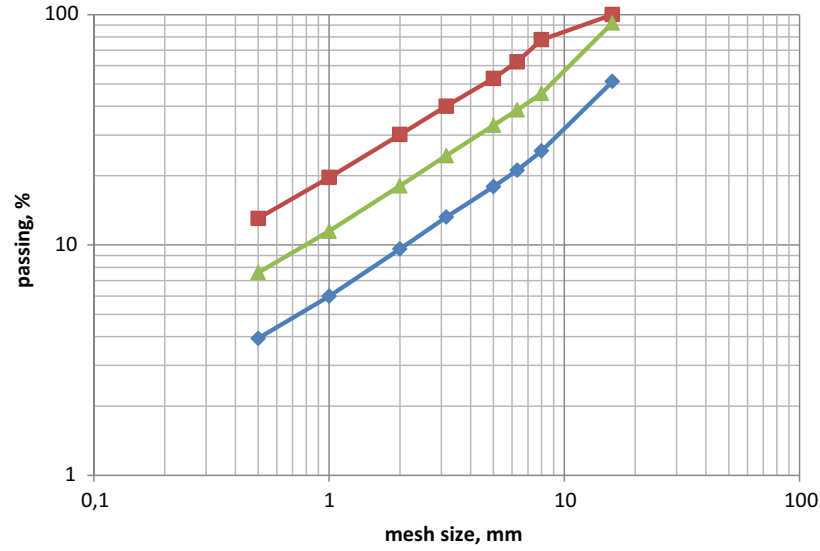

Fig. 5: PSD for the bulk jaw crusher products of limestone at three different energy levels

that even this rather low number of single particle tests may be sufficient for determining the naturally occurring steepest possible slope of the PSD at small particle sizes.

\subsection{Limestone and Amphibolite}

Sieve analysis was done separately for the single particle tests. The percent passing were then averaged. Fig. 4 and 5 show the PSDs for limestone after the drop weight and the bulk jaw crusher test. The sequence of energy levels is obvious for both devices. The same unambiguity is present for the amphibolite tests.

\section{Discussion}

\subsection{Specific Energy from Drop Weight vs. PSD}

While selecting test particles of similar size out of a batch is rather straightforward with bagged samples, this was virtually impossible with hot sinter. Nevertheless, at least some relationship between energy level and resulting PSD of the sinter was expected.

The passing at $10 \mathrm{~mm}-\mathrm{p}_{10}$ - was chosen as the characteristic for this comparison. Plotting the data points of every test separately would introduce considerable scatter, but a trend should be visible. However, as no relationship was detected, $\mathrm{p}_{10}$ was replaced by $\mathrm{t}_{10}$ - see section 2.3.1 which would take into account the size of the parent particle (Fig. 6). Again, no relationship was observed. In a later test series ten sinter particles each were treated with 10,20, and $30 \mathrm{~J} / \mathrm{kg}$, respectively. The averaged PSDs were very close despite the factor of 3 in energy level and at some mesh sizes the series with highest energy level is in the centre.

Contrary to sinter, both limestone and amphibolite do exhibit the expected relationship excellently (Fig. 7).

As the limitations on the accuracy of dropping the weight correctly apply equally to sinter and the latter samples and as the number of averaged tests is similar, most likely the nature of the sinter samples is to be blamed. Although differences in chemical composition may be partly respon- 


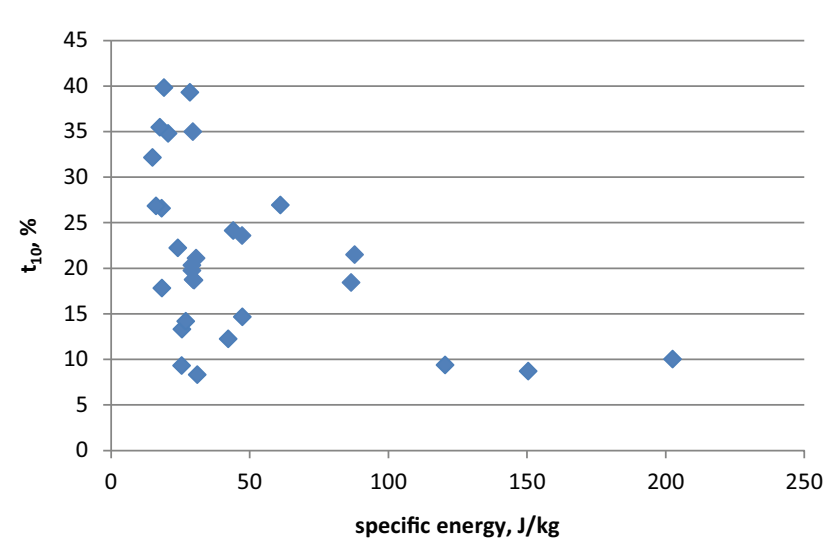

Fig. 6: $t_{10}$ vs. specific energy for drop weight tests with hot sinter

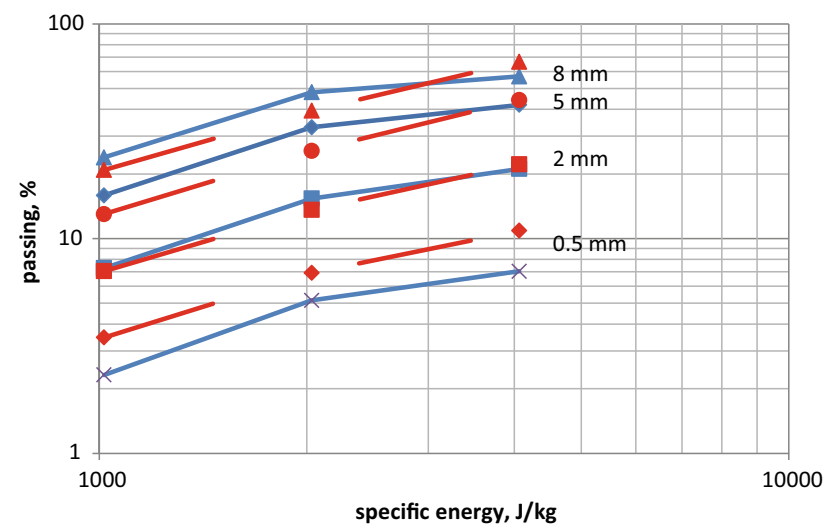

Fig. 7: Response of passing at $0.5,2,5$, and $8 \mathrm{~mm}$ to variation of specific energy in drop weight for limestone (solid) and amphibolite (dashed)

sible, the main reason will be the temperature/strength relationship of sinter. Revealing the characteristic crushing behaviour would require a much larger number of tested specimens in order to counter the heterogeneity of hot sinter.

\subsection{Modelling of Sinter Crushing via $t_{10}$}

In order to create a usable model, the standard drop weight test routine at JKMRC comprises 20 to 50 particles per size/ specific energy combination. This requires typically 500 to 1300 particles or 50 to $100 \mathrm{~kg}$ of material [3, p 77]. If the material tested was more homogeneous, even such a small number of single tests should indicate some relation.

Given the very heterogeneous nature of hot sinter, the sample size required for any meaningful results would be much larger, thus increasing the inevitable tedious and time consuming test work even more. As a more sophisticated drop weight tester or even completely different device such as the relatively recent JKRBT tester [4] would not stand the rough conditions at hand, modelling the comminution behaviour of hot sinter based on such a data set is quite out of the question.

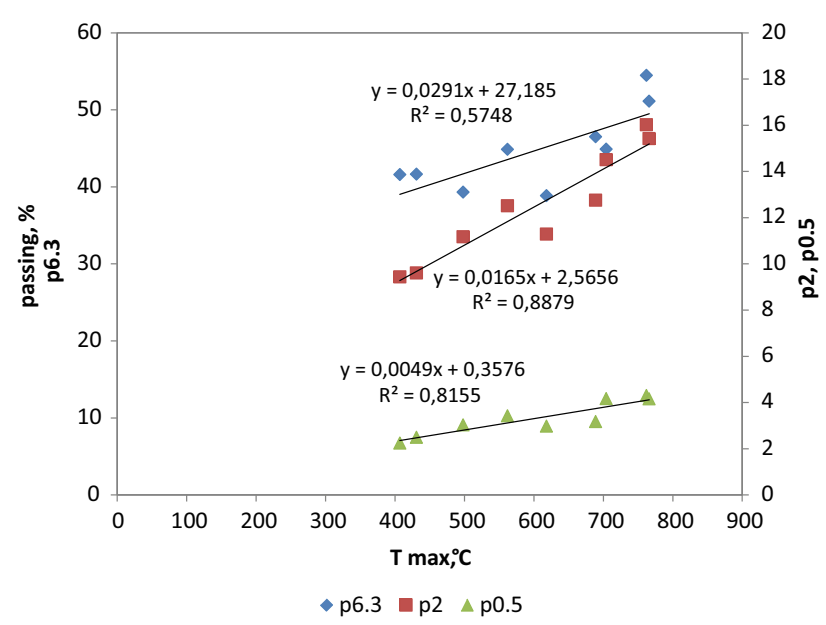

Fig. 8: Response of percent passing after jaw crusher to sinter temperature

\subsection{Influence of Sinter Temperature on Crushing}

The comminution properties of the sinter depend on its temperature, as is demonstrated in Fig. 8. Prior to being fed to the jaw crusher, ten specimens of hot sinter were documented with thermal imaging. The percent passing at $6.3,2$, and $0.5 \mathrm{~mm}$ was plotted against the maximum temperature recorded in the image. Correlation with the passing at 2 and $0.5 \mathrm{~mm}$ is strong and positive.

Similar evaluation of the drop weight tests does not yield conclusive information. However, the share of specimens that do not break at the first drop and thus the strength of sinter definitely rises with temperature.

Both the finer PSD and higher strength of hot sinter have to be taken into account in the design of an appropriate crushing circuit.

\subsection{Drop Weight vs. Crusher for Limestone and Amphibolite}

The relation of percent passing and energy level on the jaw crusher (Fig. 9) is equally clear as with the drop weight. Currently the reason for the deviation of the graphs for the two devices is not known. The basic difference between single particle and multi particle comminution might kick in here, requiring further investigation.

\subsection{Drop Weight in Closed Circuit Comminution}

Recent test work at the Chair of Mineral Processing at Montanuniversitaet Leoben has demonstrated the excellent agreement of a drop weight test and a laboratory rod mill; both performed in closed circuit and the closing mesh size being $1 \mathrm{~mm}$ [5]. A monolayer of sample $+4-6.3 \mathrm{~mm}$ was filled into a steel mortar and loaded with $2.47 \mathrm{kWh} / \mathrm{t}$ while the rod mill used $2.22 \mathrm{kWh} / \mathrm{t}$ for grinding a $+4-8 \mathrm{~mm}$ feed from the same sample to $1 \mathrm{~mm}$. For the resulting PSDs see Fig. 10. This instance indicates that a drop weight 


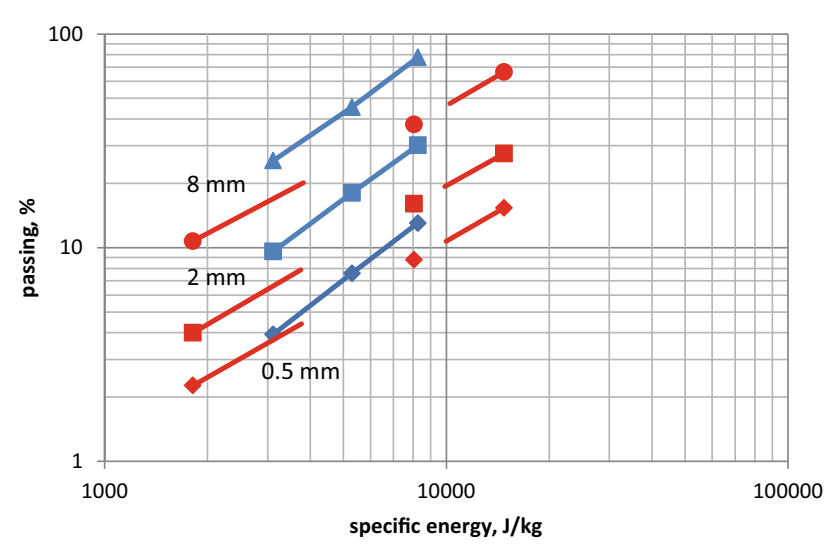

Fig. 9: Response of passing at $0.5,2$, and $8 \mathrm{~mm}$ to variation of specific energy in the jaw crusher for limestone (solid) and amphibolite (dashed)

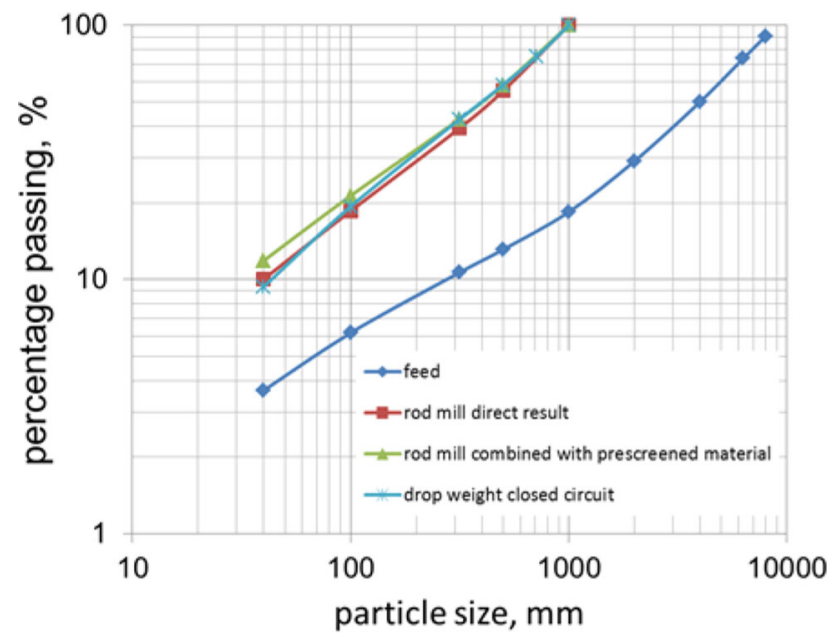

Fig. 10: PSD from closed circuit drop weight tester [5] test might well be suitable for characterizing the crushing behaviour at a rather coarse particle size but with a small sample size and little equipment.

\section{Planned Further Investigations}

Test work at the Chair of Mineral Processing has traditionally been performed in small scale. Therefore reliable testing of rocks for their crushing characteristics at a larger size than about $50 \mathrm{~mm}$ has not been possible yet for the lack of equipment and the necessary infrastructure. The results from limestone and amphibolite on the one hand and from closed circuit drop weight on the other hand are encouraging and it seems feasible to expand test work into that direction.

\section{Summary}

As the replacement of the current crushing circuit in a sinter plant has been considered, characterization of the sinter's crushing properties was called for. Its temperature is known to affect those properties, so testing specimens directly in plant was done with a very basic but sturdy drop weight tester. The sinter proved too heterogeneous to be characterized by the used small sample sizes. Although establishing the data set aimed for in the first place failed, some useful data could be collected.

The testing series performed also triggered a comparison of the drop weight with a laboratory jaw crusher using two samples of limestone and amphibolite. These results are conclusive and encourage further investigations towards testing coarser rock samples for crushability using considerably smaller sample masses than required for pilot scale crushers.

\section{Acknowledgements}

Part of the investigations presented in this paper was funded by the research programme "K1-MET" within the Austrian "Competence Centers for Excellent Technologies", COMET. The authors wish to thank their project partner voestalpine Stahl $\mathrm{GmbH}$ for the cooperation and permission to publish the results.

Open AccessThis article is distributed under the terms of the Creative Commons Attribution 4.0 International License (http://creativecommons.org/licenses/by/4.0/), which permits unrestricted use, distribution, and reproduction in any medium, provided you give appropriate credit to the original author(s) and the source, provide a link to the Creative Commons license, and indicate if changes were made.

\section{References}

1. Zaunrith, G. A.: Vergleich des Zerkleinerungsverhaltens von Laborbackenbrecher und Fallhammer anhand von Referenzproben, Bachelorarbeit, Leoben, Montanuniversität, Lehrstuhl für Aufbereitung und Veredlung, 2015

2. Böhm, A.; Mayerhofer, R.; Öfner, W.: Optimized Comminution Sequence - Natural Breakage characteristic - Energy register function. Mid-term report for EU-project “Less Fines", GRD-2000-25224, Leoben, Montanuniversität, 2002

3. Napier-Munn, T. J.; Morrell, S.; Morrison, R.D.; Kojovic, T.: Mineral Comminution Circuits. Their Operation and Optimisation, 1st edition, reprinted, Indooroopilly, Queensland, Australia: Julius Kruttschnitt Mineral Research Centre, 1999

4. Shi, F; Kojovic, C.; Larbi-Bram, S.; Manlapig, E.: Development of a rapid particle breakage characterization device - The JKRBT, Minerals Engineering 22 (2009), pp. 602-612

5. Böhm, A.: Grinding Coarse, in: Flachberger, H. (ed.): Aufbereitung in Österreich III - Dekadenbericht 2005 bis 2015, Leoben: Lehrstuhl für Aufbereitung und Veredlung, 2015, pp. 19-22 